\title{
Vulvar Small Cell Carcinoma
}

National Cancer Institute

\section{Source}

National Cancer Institute. Vulvar Small Cell Carcinoma. NCI Thesaurus. Code C128244.

A neuroendocrine carcinoma that arises from the vulva. It is characterized by the presence of malignant small cells with neuroendocrine differentiation. Most small cell neuroendocrine carcinomas of the vulva are Merkel cell carcinomas. 